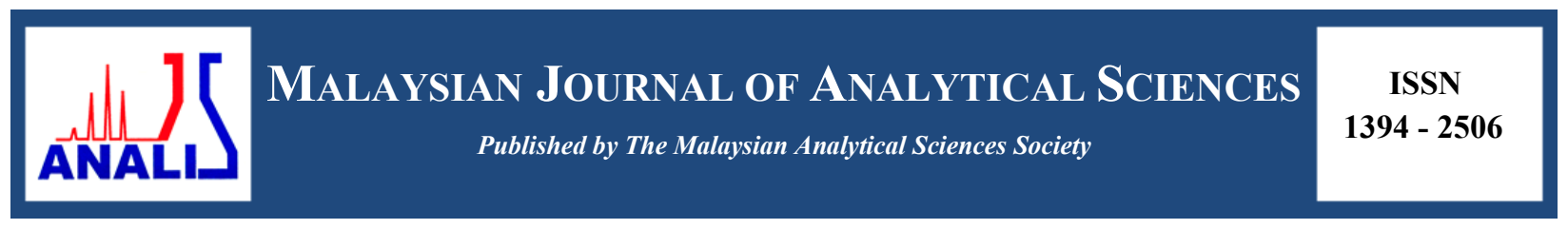

\title{
ENHANCED REDUCIBILITY OF Mg-DOPED MoVTeNbOx MIXED OXIDE CATALYSTS FOR PROPANE OXIDATION REACTION
}

\author{
(Penambahbaikan Kebolehturunan Mangkin Mg-Terdop-MoVTeNbOx Terhadap Proses \\ Pengoksidaan Propana) \\ Wong Hong Ren, Irmawati Ramli*, Taufiq Yap Yun Hin \\ Centre of Excellence for Catalysis Science and Technology, \\ Department of Chemistry, Faculty of Science, \\ Universiti Putra Malaysia, 43400 UPM Serdang, Selangor, Malaysia \\ *Corresponding author: irmawati@upm.edu.my
}

Received: 17 August 2015; Accepted: 29 August 2016

\begin{abstract}
A series of magnesium-doped MoVTeNbOx (MVTN-Mg) catalysts, as well as undoped sample (MVTN) was prepared by microwave-assisted slurry method followed by calcination in nitrogen at $873 \mathrm{~K}$ for 2 hours. The catalysts were further posttreated in aqueous hydrogen peroxide. The physicochemical properties of the catalysts were investigated using X-ray diffraction (XRD), surface area measurement using Brunauer-Emmett-Teller (BET) method, Fourier Transform Infrared (FTIR) and Field Emission Scanning Electron Microscopy (FESEM) which showed the formation of orthorhombic M1 phase, $\mathrm{Te}_{2} M_{20} \mathrm{O}_{57}(M=$ $\mathrm{Mo}, \mathrm{V}$ or $\mathrm{Nb}$ ) when doped with $\mathrm{Mg}$ at a molar ratio of $\mathrm{Mg} / \mathrm{Mo}$ of 0.06 . Temperature Programmed Reduction in hydrogen $\left(\mathrm{H}_{2}-\right.$ TPR) results indicated the enhanced reducibility of the $\mathrm{Mg}$ doped catalysts as opposed to the undoped ones, signifying the apparent high activity of the catalyst.
\end{abstract}

Keywords: magnesium, dopant, microwave-assisted slurry method, reducibility, propane oxidation

\section{Abstrak}

Mangkin MoVTeNbOx (MVTN) dan mangkin MoVTeNbOx yang didopkan magnesium (MVTN-Mg) telah dihasilkan melalui kaedah buburan berbantukan oleh penyinaran gelombang mikro. Prekursor telah dikalsinkan dalam nitrogen pada suhu $873 \mathrm{~K}$ and seterusnya dirawat dengan hidrogen peroksida. Sifat fisikokimia mangkin yang dikaji dengan menggunakan pembelauan sinar-X (XRD), pengukuran luas permukaan dengan kaedah Brunauer-Emmett-Teller (BET), spektroskopi inframerah transformasi Fourier (FTIR) dan medan elektron-mikroskopi imbasan elektron (FESEM) menunjukkan pembentukan fasa ortorombik M1, $\mathrm{Te}_{2} \mathrm{M}_{20} \mathrm{O}_{57}(M=\mathrm{Mo}, \mathrm{V}$ atau $\mathrm{Nb})$ apabila mangkin didopkan magnesium dengan nisbah molar $\mathrm{Mg} / \mathrm{Mo}$ adalah 0.06. Keputusan penurunan terprogram suhu dengan hidrogen $\left(\mathrm{H}_{2}-\mathrm{TPR}\right)$ mendedahkan penambahbaikan kebolehturunan mangkin $\mathrm{Mg}-\mathrm{MoVTeNbOx}$ berbanding dengan mangkin tanpa dopan dan dengan demikian ini menandakan aktiviti mangkin yang tinggi.

Kata kunci: magnesium, dopan, kaedah buburan dibantu oleh penyinaran gelombang mikro, kebolehturunan, pengoksidaan propana

\section{Introduction}

Multicomponents MoVTeNbOx catalysts have been recognized as the most promising catalyst in giving high activity and selectivity in propane partial oxidation to acrylic acid [1]. Typically, MoVTeNbOx catalysts present as main crystalline phases of orthorhombic $\mathrm{M} 1$ phase $\mathrm{Te}_{2} M_{20} \mathrm{O}_{57}(M=\mathrm{Mo}, \mathrm{V}$ or Nb) [2-11] and hexagonal M2 phase 
$\mathrm{Te}_{0.33} M \mathrm{O}_{3.33}(M=\mathrm{Mo}, \mathrm{V}$ or $\mathrm{Nb})$ [4-10]. Each of the individual elements in the mixed oxide catalysts has its own role in converting propane to acrylic acid. It was proposed that propane adsorbed on the $\mathrm{V}^{5+}$ site of the catalyst surface through the formation of resonance structure with $\mathrm{V}^{4+}$, hence the catalyst must be in a reduced state. $\mathrm{Te}^{4+}$ strategically positioned with the bonding distance of its surface, abstract the $\alpha$-hydrogen of propane to form propylene [12]. Further process is followed by the insertion of oxygen at $\mathrm{Mo}^{6+}$ site, thus forming acrolein and followed by another oxygen insertion at the same site to form acrylic acid [13]. $\mathrm{Nb}^{5+}$ site is needed to stabilize the product (acrylic acid) from further oxidation into $\mathrm{CO}$ and $\mathrm{CO}_{2}$ [14]. The ability of MoVTeNbOx to be reduced is a prime condition for a successful catalyst as this will activate it into reacting with the incoming reactant (propane). The reducibility of the catalyst is determined by subjecting it into reducing environment such as $\mathrm{CO}$ and hydrogen followed by the quantification of the amount of oxygen removed. The onset of reduction process and the peak maxima for the reduction give an indication of the extent of reduction of the metal oxides.

The catalyst properties may also be further improved by the introduction of metal ions into the lattice [15-21]. Promoter such as cobalt has been reported successful in modifying the properties of $(\mathrm{VO})_{2} \mathrm{P}_{2} \mathrm{O}_{7}$ through the formation of crystalline form of $\mathrm{V}^{4+}$ (vanadyl pyrophosphate, $(\mathrm{VO})_{2} \mathrm{P}_{2} \mathrm{O}_{7}$ ), $\mathrm{CoPO}_{4}$ phase and a small amount of $\mathrm{V}^{5+}$ $\left(\beta-\mathrm{VOPO}_{4}\right.$ phase). It also plays a role in having an effect on the reducibility of the catalyst through oxygen diffusion within the lattice of the $(\mathrm{VO})_{2} \mathrm{P}_{2} \mathrm{O}_{7}$ catalyst that have dramatically increased the specific rate of butane oxidation into forming maleic anhydride three times as compared to the undoped ones [22]. There is also a study done on incorporating potassium into the MoVSb mixed oxide catalysts to affect the catalytic ability. It was found that the conversion of propane was slightly decreases. However, with an appropriate amount of this alkaline metal, it drastically increases the selectivity of acrylic acid about 2 to 3 times as compared to undoped catalysts. In addition, a decrease in the selectivity of undesired products (acetic acid, carbon monoxide and carbon dioxide) could be seen [23-26].

Pure M1 phase MoVTeNbOx can be obtained directly by hydrothermal synthesis $[27,28]$ in an autoclave heated at $448 \mathrm{~K}$ in a nitrogen atmosphere with a synthesis time of $72 \mathrm{~h}$. The synthesis method is mainly characterized by its high solvent effect and equilibrium conditions which lead to the formation of the favoured crystalline phase. Another approach is by using a slurry method [29,30] on the basis of a non-solution precursor. This condition inevitably contributes to the multiphase MoVTeNbOx system in which the species is always present in different valence states due to its non-equilibrium state.

In the present work, a microwave-assisted slurry method has been developed for the synthesis of MoVTeNbOx catalysts, promoted and undoped ones. The method allows intimate mixing of the metal species in a homogeneous state under atmospheric pressure in a very short time. This method is derived from the patented method developed by this research group [31].

\section{Catalysts preparation}

\section{Materials and Methods}

The undoped (MVTN) and magnesium-promoted MoVTeNbOx (MVTN-Mg) catalysts with a $\mathrm{Mo} / \mathrm{V} / \mathrm{Te} / \mathrm{Nb} / \mathrm{Mg}$ molar ratio of $1 / 0.3 / 0.23 / 0.12 / \mathrm{x}(\mathrm{x}=0.02,0.04,0.06,0.08,0.10)$ were prepared via microwave assisted slurry method. Ammonium heptamolybdate tetrahydrate, $\left(\mathrm{NH}_{4}\right)_{6} \mathrm{Mo}_{7} \mathrm{O}_{24} \cdot 4 \mathrm{H}_{2} \mathrm{O}$ (Merck), ammonium metavanadate, $\left(\mathrm{NH}_{4}\right) \mathrm{VO}_{3}$ (Merck), telluric acid, $\mathrm{Te}(\mathrm{OH})_{6}$ (Sigma-Aldrich), ammonium niobium oxalate, $\left(\mathrm{NH}_{4}\right)_{2} \mathrm{Nb}_{2}\left(\mathrm{C}_{2} \mathrm{O}_{4}\right)_{5}$ (Sigma-Aldrich), and magnesium nitrate hexahydrate, $\mathrm{Mg}\left(\mathrm{NO}_{3}\right)_{2} \cdot 6 \mathrm{H}_{2} \mathrm{O}$ (Bendosen Laboratory Chemicals) were used as metal sources for each of the elements. Appropriate amount of different metal salts was added in sequence into deionized water beginning ammonium heptamolybdate tetrahydrate and followed by ammonium metavanadate, telluric acid and magnesium nitrate hexahydrate to give solution A. Each time after the metal salt was added, the solution was subjected to microwave irradiation for 1.5 minutes. While solution B was obtained by dissolving ammonium niobium oxalate in deionized water and was also subjected to 1.5 minutes microwave irradiation. After that, the two solutions were mixed and the resulting orange slurry was aged for overnight to homogenise the particle distribution. The slurry was then dried by using a rotary evaporator at $353 \mathrm{~K}$ to give a sample precursor. Calcination was then carried out to the precursor where it was heated at $553 \mathrm{~K}$ for $1 \mathrm{~h}$ in air and at $873 \mathrm{~K}$ for $2 \mathrm{~h}$ under nitrogen flow. Post treatment process was done by washing the solid with $30 \%$ hydrogen peroxide. The peroxide was 
removed through centrifugation, and the solid was dried in an oven at $373 \mathrm{~K}$ for overnight. The $\mathrm{Mg}$ containing catalysts are designated as MVTN-Mg(x), $\mathrm{x}$ being the $\mathrm{Mg} / \mathrm{Mo}$ molar ratio.

\section{Catalysts characterization}

The BET surface area of the catalysts was determined by using a Thermo Finnigan Sorptomatic Instrument model 1990 series with adsorption of nitrogen at $77 \mathrm{~K}$.

Powder X-ray diffraction (XRD) patterns were collected by employing a Shimadzu 6000 X-ray diffractometer using Ni filtered $\mathrm{CuK}_{\alpha}$ radiation with wavelength $\lambda=1.542 \AA$. The catalysts were ground and put on a horizontal sample holder. The XRD patterns were recorded in the $2^{\circ}$ to $60^{\circ} 2 \Theta$ range at a scanning rate of $2.0^{\circ} \mathrm{min}^{-1}$.

Fourier-Transform Infrared (FT-IR) analysis was carried out at room temperature in the $280-4000 \mathrm{~cm}^{-1}$ region with a Perkin Elmer 1725X spectrophotometer. The pellets were prepared with mixing a catalyst sample with $200 \mathrm{mg}$ of dry $\mathrm{KBr}$ and pressed into disks.

The morphology of the catalysts was obtained by using a Nova 200 Nanolab Field Electron Scanning Electron Microscope (FE-SEM). The surface catalyst images were recorded at an accelerating voltage of $15 \mathrm{kV}$ and magnification of 100,000 .

\section{Reducibility study}

Temperature programmed reduction in hydrogen $\left(\mathrm{H}_{2}-\mathrm{TPR}\right)$ was performed by using a Thermo Finnigan TPDRO 1100 apparatus, utilizing a thermal conductivity detector (TCD). Before subjecting the catalysts to the reducing gas, the samples were first treated by flowing nitrogen at room temperature for half an hour to remove any weak species that might present on the surface. After which the nitrogen gas flow was switched to $5.1 \% \mathrm{H}_{2}$ in argon gas with a flow rate of $25 \mathrm{ml} \mathrm{min}^{-1}$ at a heating rate of $10 \mathrm{~K} \mathrm{~min}^{-1}$ from room temperature up to $1223 \mathrm{~K}$. The mass spectrometer records the evolution of water continuously during the course of the reaction.

\section{Characterisation of as-synthesised samples}

\section{Results and Discussion}

XRD patterns of the as-synthesised samples (before calcination) are displayed in Figure 1. The reflections are found in the $2 \theta=5-15^{\circ}$ and $25-30^{\circ}$ range. These reflections are typical of Anderson-type structure $\left(\mathrm{NH}_{4}\right)_{6} \mathrm{TeMo}_{6} \mathrm{O}_{24} .7 \mathrm{H}_{2} \mathrm{O}$ as reported by Evans et al. [32] and $\left(\mathrm{NH}_{4}\right)_{7} \mathrm{TeMo}_{5} \mathrm{VO}_{24} .8 \mathrm{H}_{2} \mathrm{O}$ reported by Sun et al. [33] which indicates the presence of heteropoly compounds (HPCs). The narrow diffractions observed in undoped sample becomes broad bands when Mg was added signifying that the HPCs slowly turns into pseudo-crystallines with increasing amount of $\mathrm{Mg}$.

Figure 2 shows the FTIR spectra of as-synthesised samples taken in the range of wavenumber $280-4000 \mathrm{~cm}^{-1}$. All samples give FTIR spectra with practically identical bands. The bands at $576 \mathrm{~cm}^{-1}$ are assigned to a $\mathrm{V}=\mathrm{O}$ group and/or V-O- $M$ bonds $(M=\mathrm{V}, \mathrm{Nb})$. Whereas the absorption bands at $483,630,678$, and $883 \mathrm{~cm}^{-1}$ could be assigned to heteropoly-telluromolybdates, $\left(\mathrm{NH}_{4}\right)_{6} \mathrm{TeMo}_{6} \mathrm{O}_{24} \cdot 7 \mathrm{H}_{2} \mathrm{O}[34,35]$ in accordance with the XRD results. The bands at $3400-3550 \mathrm{~cm}^{-1}$ are associated to the symmetric and anti-symmetric $\mathrm{O}-\mathrm{H}$ bending modes of lattice water, while the bands at $1650 \mathrm{~cm}^{-1}$ could be related to $\mathrm{H}-\mathrm{O}-\mathrm{H}$ bending modes [36,37]. Additionally, the asymmetric and symmetric stretching vibration of ammonium cation $\left(v\left(\mathrm{NH}_{4}{ }^{+}\right)\right)$are determined by the band at $1425 \mathrm{~cm}^{-1}$, and at 3000 and 3200 $\mathrm{cm}^{-1}$ respectively [34-36]. 


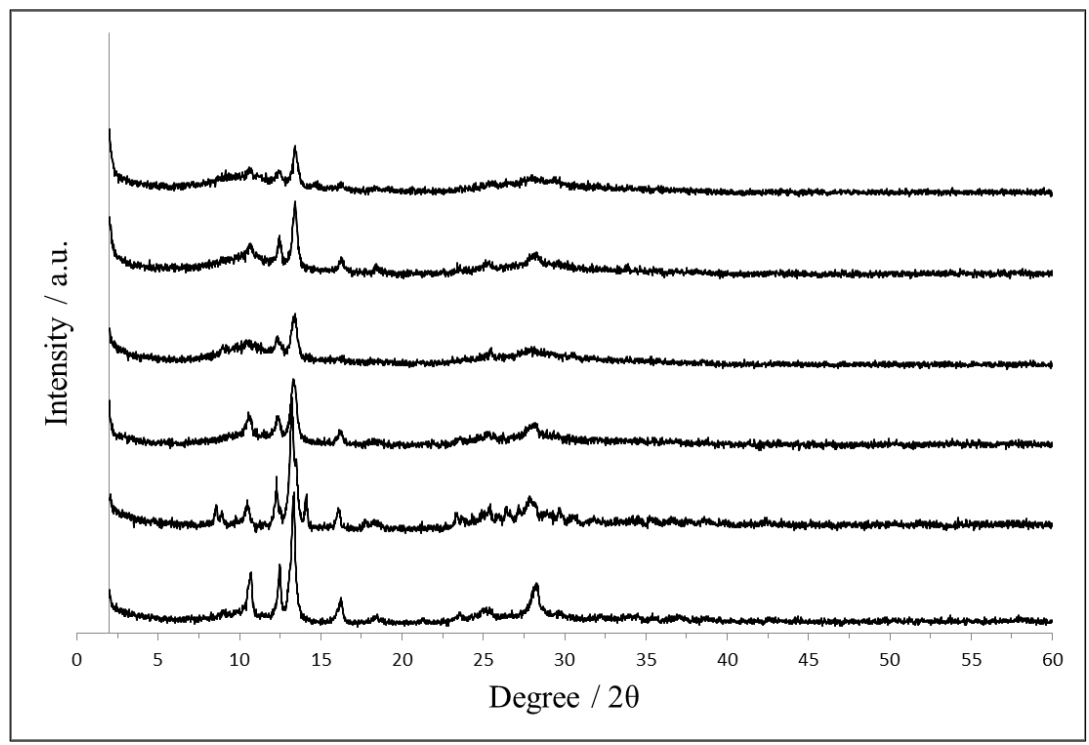

Figure 1. XRD patterns of magnesium free and magnesium containing catalyst precursors: (a) MVTN, (b) MVTNMg (0.02), (c) MVTN-Mg (0.04), (d) MVTN-Mg (0.06), (e) MVTN-Mg (0.08) and (f) MVTN-Mg (0.10)

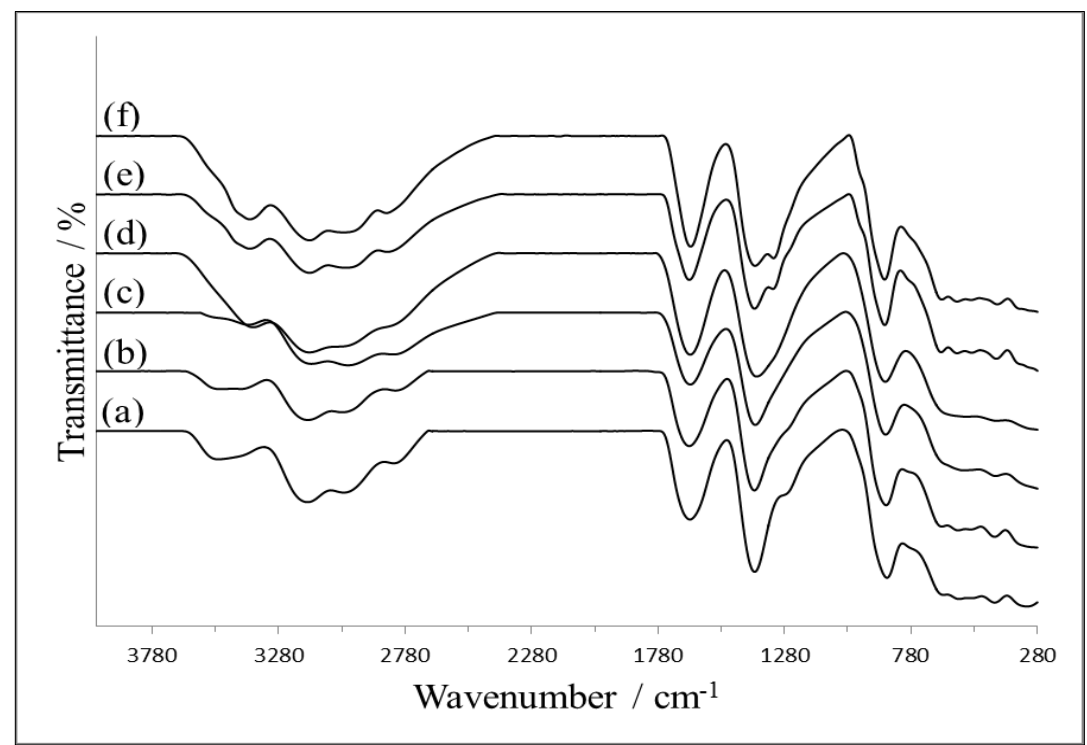

Figure 2. FTIR spectra of magnesium free and magnesium containing catalyst precursors: (a) MVTN, (b) MVTNMg (0.02), (c) MVTN-Mg (0.04), (d) MVTN-Mg (0.06), (e) MVTN-Mg (0.08) and (f) MVTN-Mg $(0.10)$.

\section{Characterization of calcined catalysts}

The XRD patterns of the calcined catalysts are shown in Figure 3. All of the samples show a similar diffraction peaks with five prominent peaks at $2 \theta=22.1^{\circ}, 28.2^{\circ}, 36.2^{\circ}, 45.0^{\circ}$ and $50.0^{\circ}$. Termed as the "famous five", however, it was reported that the MoVTeNbOx catalysts containing these peaks did not work effectively [38], 
suggesting they are not the key drivers of a successful MoVTeNb mixed oxide catalysts. These five peaks associated with the presence of hexagonal $\mathrm{M} 2, \mathrm{Te}_{0.33} M \mathrm{O}_{3.33}(M=\mathrm{Mo}, \mathrm{V}$ and $\mathrm{Nb})$ phase [39-41] which is isomorphous to that of $\mathrm{Sb}_{4} \mathrm{M}_{10} \mathrm{O}_{31}$ phase [10], and hexagonal tungsten bronze (HTB)-type phase [42]. The formation of M2 phase is common since it is usually started to form at $723 \mathrm{~K}$ [43]. It is also noted the development of new peaks in the range of $2 \theta=6.7-10.0^{\circ}$. These peaks are assigned to orthorhombic $\mathrm{M} 1, \mathrm{Te}_{2} M_{20} \mathrm{O}_{57}(M=\mathrm{Mo}, \mathrm{V}$ and $\mathrm{Nb})$ phase $[43,44]$.

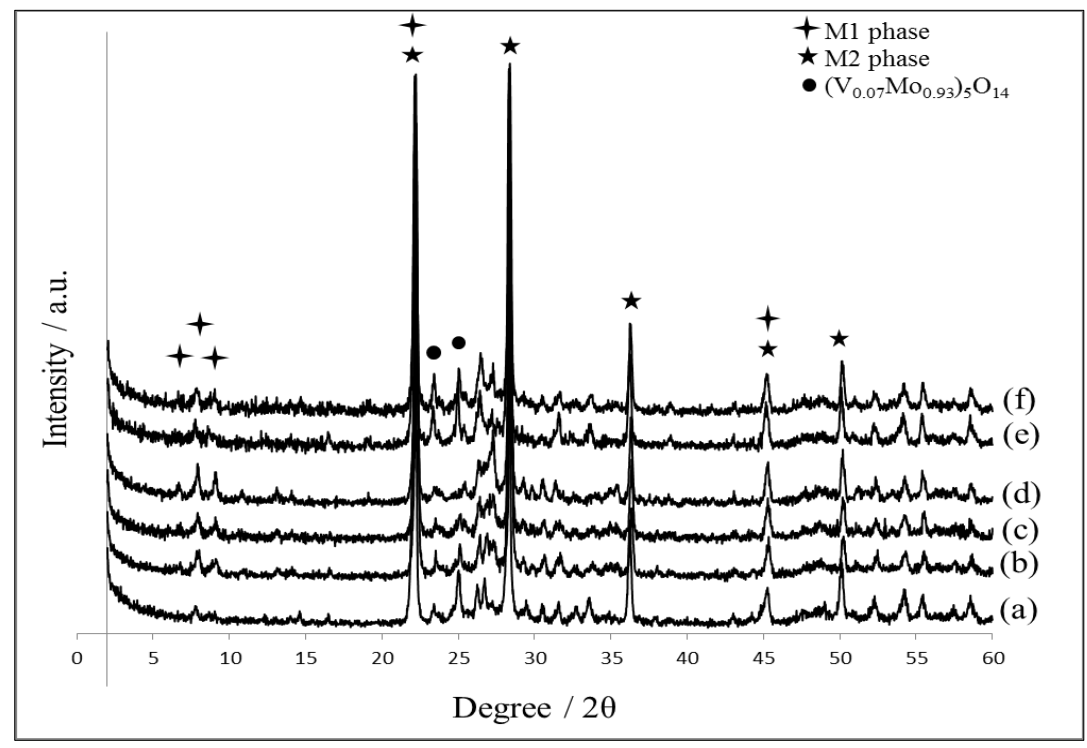

Figure 3. XRD patterns of magnesium free and magnesium containing calcined catalysts: (a) MVTN, (b) MVTNMg (0.02), (c) MVTN-Mg (0.04), (d) MVTN-Mg (0.06), (e) MVTN-Mg (0.08) and (f) MVTN-Mg $(0.10)$.

In the case of post-treated catalysts, $\mathrm{Te}_{2} M_{20} \mathrm{O}_{57}(M=\mathrm{Mo}, \mathrm{V}$ and $\mathrm{Nb})$ orthorhombic M1 was the crystalline phase mainly observed (Figure 4) which can be identified with the peaks at $2 \theta=6.7^{\circ}, 7.8^{\circ}, 9.0^{\circ}, 22.1^{\circ}, 26.2^{\circ}, 26.8^{\circ}, 27.2^{\circ}$, $29.2^{\circ}$ and $35.4^{\circ}$ [7]. Thus it can be concluded that the post treatment with an aqueous solution of hydrogen peroxide leads to the selective removal of the hexagonal M2 phase from the Mg-doped and undoped MoVTeNbOx catalysts containing M1 and M2 phase mixtures [45]. However, additional phase of tetragonal $\left(\mathrm{V}_{0.07} \mathrm{Mo}_{0.93}\right)_{5} \mathrm{O}_{14}$ (JCPDS File No. 31-1473) can be found. Comparison of the XRD patterns of the Mg-promoted with undoped catalysts revealed that the appearance of phase reflections at $2 \theta=23.3,24.6$ and $31.5^{\circ}$ in undoped catalysts corresponds to the rich tetragonal $\left(\mathrm{V}_{0.07} \mathrm{Mo}_{0.93}\right)_{5} \mathrm{O}_{14}$ phase. This phase was slightly diminished when $\mathrm{Mg}$ was added until the molar ratio of $\mathrm{Mg} / \mathrm{Mo}$ was 0.06 , suggesting the incorporation of $\mathrm{Mg}$ in catalyst lattice is responsible for the suppression of the tetragonal crystallization step. However, beyond that amount (molar ratio $=0.06$ ) the crystallization of tetragonal phase was started to taken over. The XRD patterns of the formed structural material of MVTN-Mg $(0.06)$ catalyst is quite similar to the one observed in the case of monophasic MoVTeNbOx orthorhombic M1 phase which were hydrothermally synthesized $[27,28]$. 


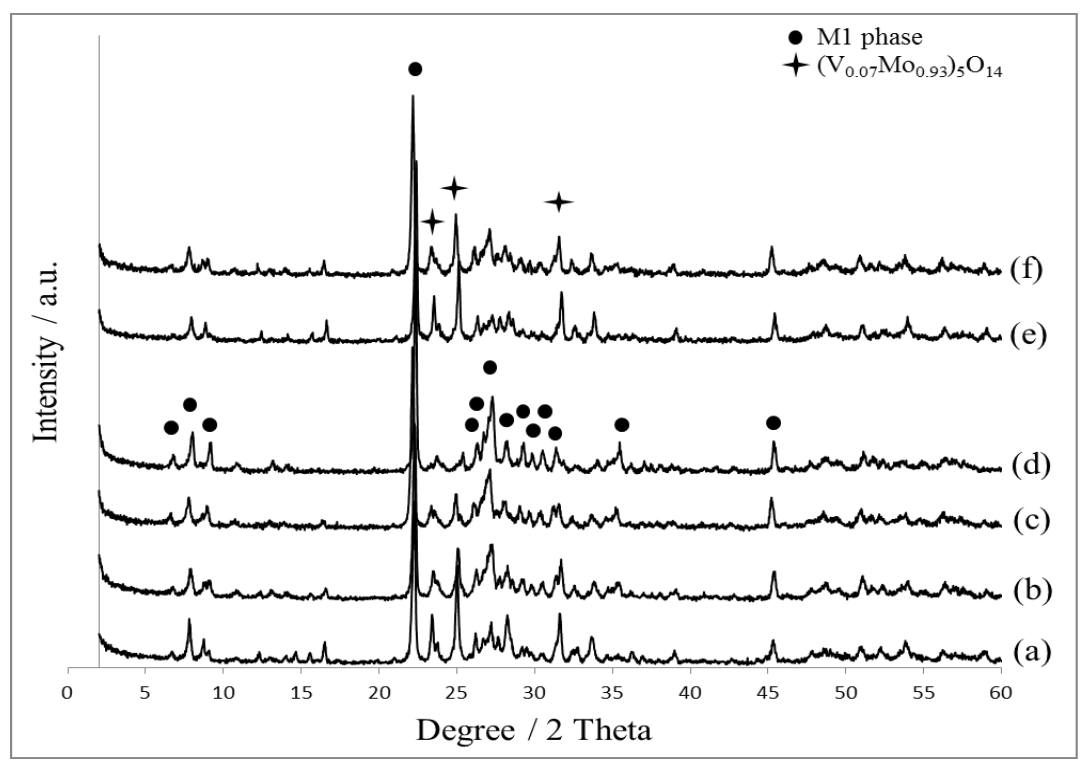

Figure 4. XRD patterns of magnesium free and magnesium containing post-treated catalysts: (a) MVTN, (b) MVTN-Mg (0.02), (c) MVTN-Mg (0.04), (d) MVTN-Mg (0.06), (e) MVTN-Mg (0.08) and (f) MVTN$\operatorname{Mg}(0.10)$

FTIR spectra of post-treated catalysts are shown in Figure 5. The FTIR spectra of bulk MVTN and MVTN-Mg samples composed of M1 and tetragonal phases show absorption bands at $357 \mathrm{~cm}^{-1}$ indicates the existence of MoO-Mo bridge with symmetric stretching vibration [34]. Meanwhile, the band that is related to the anti-symmetric vibration of Mo-O- $M(M=\mathrm{V}, \mathrm{Nb}, \mathrm{Te})$ bridging bonds which appear around $700-900 \mathrm{~cm}^{-1}$ is observed at $745 \mathrm{~cm}^{-1}$. The bands at $560 \mathrm{~cm}^{-1}$ may probably presents a $\mathrm{V}=\mathrm{O}$ group and/or $\mathrm{V}-\mathrm{O}-M(M=\mathrm{Mo}, \mathrm{Nb}, \mathrm{Te})$ bonds. The symmetric stretching vibration of $\mathrm{Mo}=\mathrm{O}$ group that is around $900-1000 \mathrm{~cm}^{-1}$ is identified by the absorption band at $910 \mathrm{~cm}^{-1}$ $[46,47]$. The most highlighted difference among IR spectra is an intensity of the bands for the catalysts containing tetragonal phase due to the improved crystallization of this phase. The broad bands at higher region (at around 3000 $\mathrm{cm}^{-1}-3400 \mathrm{~cm}^{-1}$ ) could be attributed as symmetric and anti-symmetric $\mathrm{O}-\mathrm{H}$ bending modes of lattice water. The absorption bands at about $1650 \mathrm{~cm}^{-1}$ could be assigned to the presence of $\mathrm{H}-\mathrm{O}-\mathrm{H}$ bending modes $[36,37]$. This is due to the incomplete drying of post-treated catalysts after washing with hydrogen peroxide. The deviation caused by the containing water was eliminated as pre-treatment was carried out before catalysts were characterised.

The morphology of post-treated catalyst was investigated by FESEM analysis. In general, all of the catalysts were found to have a similar morphology of small rod shaped crystallites as shown in Fig. 6. Such kind of morphology was already been reported by López Nieto and his research team, and are commonly observed for M1 phase crystals [48]. The particle size is rather homogeneous with apparent edges and pointed corners that agreed well with the sharp peaks observed in XRD results. There is no clear effect of the addition of promoter to the catalyst morphology. 


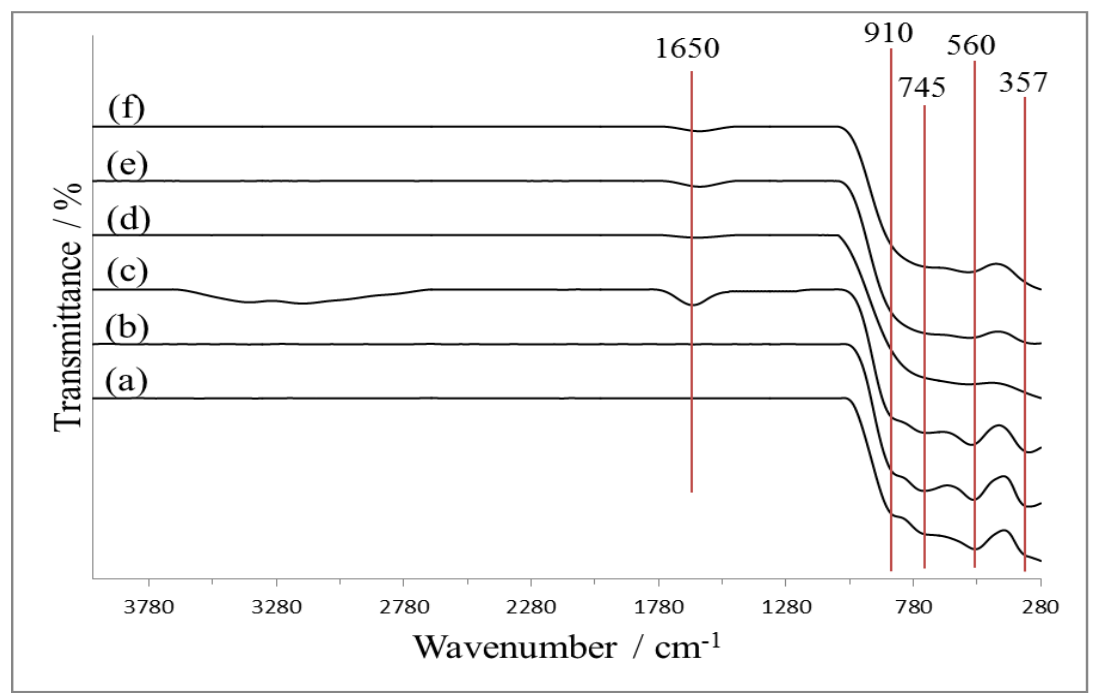

Figure 5. FTIR spectra of magnesium free and magnesium containing post-treated catalysts: (a) MVTN, (b) MVTN-Mg (0.02), (c) MVTN-Mg (0.04), (d) MVTN-Mg (0.06), (e) MVTN-Mg (0.08) and (f) MVTN$\operatorname{Mg}(0.10)$
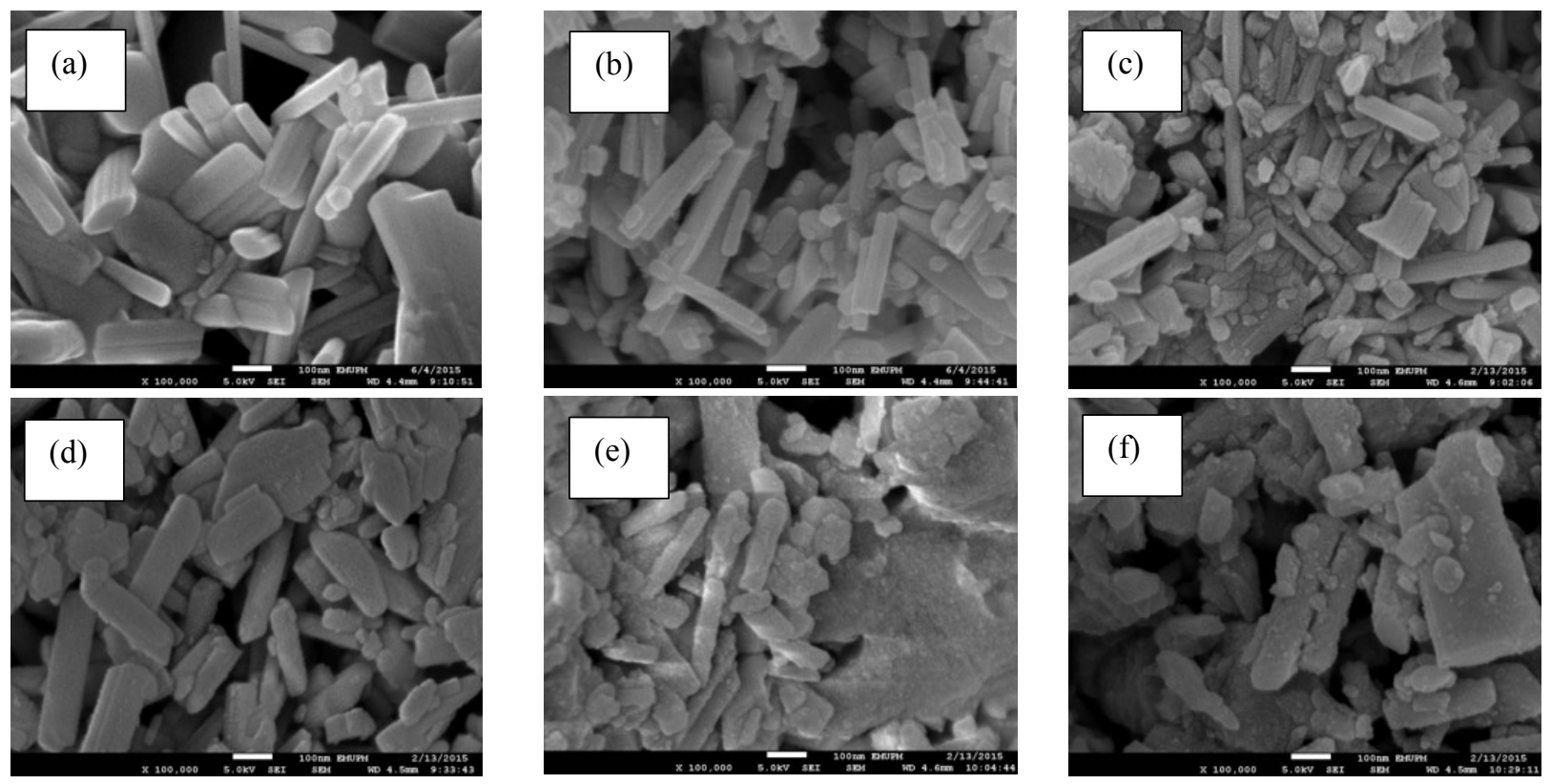

Figure 6. FESEM images of magnesium free and magnesium containing post-treated catalysts: (a) MVTN, (b) MVTN-Mg (0.02), (c) MVTN-Mg (0.04), (d) MVTN-Mg (0.06), (e) MVTN-Mg (0.08) and (f) MVTN-Mg (0.10)

BET surface area of MVTN and MVTN-Mg catalysts are shown in Table 1. Low surface area $\left(3.3-4.2 \mathrm{~m}^{2} \mathrm{~g}^{-1}\right)$ is observed in all calcined samples. Therefore, there is no significant effect of magnesium addition to the catalyst crystal structure. However, when the catalysts were post-treated with hydrogen peroxide, the surface area value 
significantly improved $\left(13.4-20.4 \mathrm{~m}^{2} \mathrm{~g}^{-1}\right)$. This could be related to the selective removal of M2 phase during the post treatment that contributed to the smaller particle size.

Table 1. General characteristics of heat-treated and post-treated catalysts

\begin{tabular}{|c|c|c|c|c|c|}
\hline \multirow[b]{2}{*}{ Catalysts } & \multicolumn{2}{|c|}{ BET Surface Area $\left(\mathrm{m}^{2} \mathrm{~g}^{-1}\right)$} & \multicolumn{3}{|c|}{ TPR Results ${ }^{\mathrm{a}}$} \\
\hline & Heat-treated & Post-treated & $\begin{array}{l}T_{\max } \\
\text { (K) }\end{array}$ & $\begin{array}{c}\mathrm{E}_{\mathrm{r}} \\
\left(\mathrm{kJ} \mathrm{mol}^{-1}\right)\end{array}$ & $\begin{array}{c}\mathrm{O}_{2} \text { Removed } \\
\left(\text { atom }^{-1} \text { ) }\right.\end{array}$ \\
\hline MVTN & 3.3 & 13.4 & 930 & 155.36 & $2.56 \times 10^{21}$ \\
\hline \multirow[t]{3}{*}{ MVTN-Mg (0.02) } & 3.9 & 20.1 & 825 & 137.82 & $1.74 \times 10^{21}$ \\
\hline & & & 908 & 151.68 & $7.72 \times 10^{20}$ \\
\hline & & & & & $2.51 \times 10^{21}$ \\
\hline \multirow[t]{3}{*}{ MVTN-Mg (0.04) } & 3.9 & 20.4 & 809 & 147.00 & $2.18 \times 10^{21}$ \\
\hline & & & 866 & 158.53 & $3.87 \times 10^{20}$ \\
\hline & & & & & $2.57 \times 10^{21}$ \\
\hline \multirow[t]{4}{*}{ MVTN-Mg $(0.06)$} & 4.2 & 18.8 & 845 & 141.16 & $3.76 \times 10^{21}$ \\
\hline & & & 902 & 150.68 & $1.64 \times 10^{21}$ \\
\hline & & & 928 & 155.02 & $1.47 \times 10^{21}$ \\
\hline & & & & & $6.87 \times 10^{21}$ \\
\hline MVTN-Mg (0.08) & 3.3 & 15.3 & 1009 & 168.55 & $4.99 \times 10^{21}$ \\
\hline MVTN-Mg $(0.10)$ & 3.6 & 21.3 & 978 & 163.38 & $5.61 \times 10^{21}$ \\
\hline
\end{tabular}

${ }^{\mathrm{a}} \mathrm{TPR}$ results of post-treated catalysts

\section{Catalyst reducibility study}

The TPR profiles of MVTN and MVTN-Mg catalysts are shown in Figure 7. The analysis was done by flowing hydrogen over the catalyst while temperature was increased at a heating rate of $10 \mathrm{~K} / \mathrm{min}$ from room temperature to $1223 \mathrm{~K}$. The hydrogen upon interacts with surface oxygen will reacts to form water as the product. The evolution of water was recorded continuously during the course of reaction.

The interaction between the gas phase hydrogen with the surface oxygen can be represented as follows:

$$
\mathrm{H}_{2}(\mathrm{~g})+\mathrm{O}(\mathrm{s}) \rightarrow \mathrm{H}_{2} \mathrm{O}(\mathrm{g})+\square
$$

where (g), (s), and $\square$ denotes gas, surface and vacancy.

Comparison of the peak profiles show that the undoped catalyst (MVTN) has a broad peak with maximum temperature $\left(T_{\mathrm{m}}\right)$ occurs at $930 \mathrm{~K}$. The catalyst is less reducible as stipulated by the slow climbing of the reduction peak. On the other hand, all of the promoted catalysts (MVTN-Mg) show a different reduction profile with the peak climbing start immediately after the catalyst started to reduced. The $T_{\mathrm{m}}$ can be found as low as $825 \mathrm{~K}$ (for sample MVTN-Mg (0.02)). There is also a presence of other peak maxima in these Mg-promoted catalysts which signify the kinetically different of oxygen species present in the catalysts. The onset of reduction for Mg-promoted catalysts was at $650 \mathrm{~K}$ which is coincidence with the reaction temperature for propane oxidation. Meanwhile, the undoped catalyst showed the onset of reduction at about $770 \mathrm{~K}$ which indicated the less reducible of this sample.

For the undoped MVTN catalyst, the reduction of pure $M O n(M=\mathrm{Mo}, \mathrm{V})$ was at $948 \mathrm{~K}$ and $995 \mathrm{~K}$ [49]. Both Mo and $\mathrm{V}$ species undergo stepwise reduction from $\mathrm{Mo}^{6+} \rightarrow \mathrm{Mo}^{4+}$ and $\mathrm{Mo}^{4+} \rightarrow \mathrm{Mo}^{0}$, and $\mathrm{V}^{5+} \rightarrow \mathrm{V}^{4+}$ and $\mathrm{V}^{4+} \rightarrow \mathrm{V}^{0}$, 
respectively. Therefore, the reduction peak observed in this catalyst at $930 \mathrm{~K}$ could be attributed to the reduction of both species. Additionally, $\mathrm{Nb}^{5+}$ might also be reduced to $\mathrm{Nb}^{4+}$ at higher reduction temperature of more than $1000 \mathrm{~K}$ as indicated by Pereira et al. [50] in their work on $\mathrm{Nb}_{2} \mathrm{O}_{5}$.

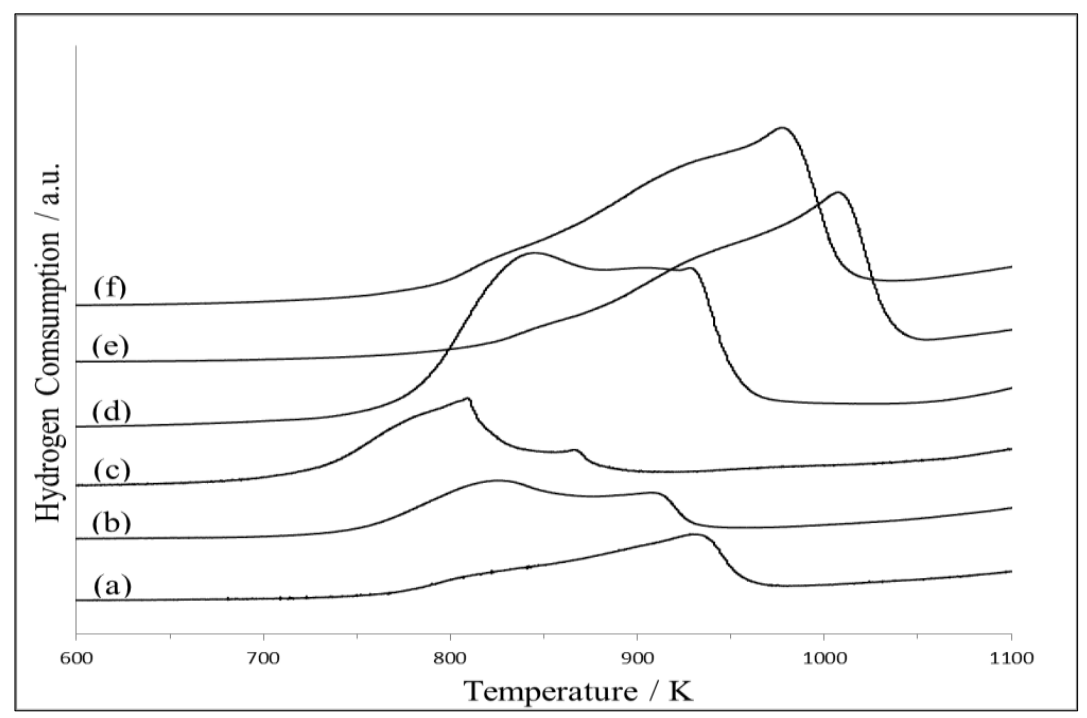

Figure 7. TPR profiles of magnesium free and magnesium containing post-treated catalysts: (a) MVTN, (b) MVTN-Mg (0.02), (c) MVTN-Mg (0.04), (d) MVTN-Mg (0.06), (e) MVTN-Mg (0.08) and (f) MVTN-Mg (0.10)

Meanwhile, the lower peak maximum given by the Mg-promoted MoVTeNbOx catalysts indicated the positive contribution of promoter. The Mg metals might be well dispersed on the catalyst's surface and formed weaker bonds with oxygen species that promote the reducibility of the catalysts. The reduction profiles of MVTN-Mg catalysts are due to the reduction of $\mathrm{MoO}_{\mathrm{n}}, \mathrm{VO}_{\mathrm{n}}, \mathrm{NbO}_{\mathrm{n}}$ and also from $\mathrm{MgO} \rightarrow \mathrm{Mg}^{0}$. For $\mathrm{MoO}_{\mathrm{n}}$, the species reduced from $\mathrm{Mo}^{6+} \rightarrow \mathrm{Mo}^{4+}$ and $\mathrm{Mo}^{4+} \rightarrow \mathrm{Mo}^{0}$, for $\mathrm{VO}_{\mathrm{n}}$, the reduction occurs from $\mathrm{V}^{5+} \rightarrow \mathrm{V}^{4+}$ and $\mathrm{V}^{4+} \rightarrow \mathrm{V}^{0}$, and $\mathrm{NbO}_{\mathrm{n}}$ reduces from $\mathrm{Nb}^{5+} \rightarrow \mathrm{Nb}^{0}[49,50]$.

The amount of removable oxygen can be quantified by calculating the area under the peak and the value of the reduction activation energy, $\mathrm{E}_{\mathrm{r}}$, can be obtained from the modified version of the Redhead equation 1:

$$
\frac{E_{r}}{R T_{m}^{2}}=\left(\frac{A_{r}}{\beta}\right)\left[H_{2}\right]_{m} \exp \left(\frac{E_{r}}{R T_{m}}\right)
$$

where $T_{\mathrm{m}}$ is the peak maximum temperature $(\mathrm{K})$ in the rate of reaction of $\mathrm{H}_{2}, E_{\mathrm{r}}$ is the reduction activation energy $\left(\mathrm{kJ} \mathrm{mol}{ }^{-1}\right), R$ is the gas constant $\left(\mathrm{J} \mathrm{K}^{-1} \mathrm{~mol}^{-1}\right), \beta$ is the heating rate $\left(\mathrm{K} \mathrm{s}^{-1}\right), \mathrm{A}_{\mathrm{r}}$ is the reduction pre-exponential term $\left(\mathrm{cm}^{3} \mathrm{~mol}^{-1} \mathrm{~s}^{-1}\right)$ which is given the value of a standard collision number of $10^{13} \mathrm{~cm}^{3} \mathrm{~mol}^{-1} \mathrm{~s}^{-1}$ and $\left[\mathrm{H}_{2}\right]_{\mathrm{m}}$ is the gas phase concentration of hydrogen $\left(\mathrm{mol} \mathrm{cm}^{-3}\right)$ at the peak maximum.

The values obtained are listed in Table 1 . The total number of oxygen atoms released by the undoped and Mgpromoted MoVTeNbOx catalysts are found similar $\left(\sim 2.56 \times 10^{21}\right.$ atom $\left.\mathrm{g}^{-1}\right)$. Close inspection revealed that the Mgpromoted catalysts are more reducible as indicated by the ability of the catalyst to be reduced at lower temperature. Hence, the oxygen species in these promoted catalysts are more labile signifying the higher activity of the promoted catalysts. It is also important to note that the MVTN-Mg (0.06) sample have the highest total amount of oxygen removed. The oxygen species in this catalyst is more reducible at lower temperature as compared to others due to the existence of orthorhombic M1 phase in this sample that facilitates the oxygen removable. 
The reduction activation energy, $E_{\mathrm{r}}$ value $>100 \mathrm{~kJ} \mathrm{~mol}^{-1}$ is high for all samples suggesting that the oxygen being removed are surface and lattice oxygen species. The circumstance that the reduction study was done in an anaerobic condition contributed to these findings. There is no weakly bonded oxygen present in these catalysts as shown by no peak evolution at lower temperature (less than $650 \mathrm{~K}$ ). Therefore, the surface and lattice oxygen removed in this works are the strongly bonded ones that could be playing an important role in the catalytic activity of the catalysts. It has been reported that the oxidation of propane to acrylic acid requires surface and lattice oxygen to be selectively inserted into the intermediate to form final product. The present of weakly bonded oxygen will somehow assist in the $\mathrm{C}-\mathrm{C}$ bond breakage that might lead to the formation of unwanted products such as acetic acid, $\mathrm{CO}$ and $\mathrm{CO}_{2}$ [51].

\section{Conclusion}

Magnesium doped MoVTeNb mixed oxides were successfully synthesized by microwave-assisted slurry method, calcined in nitrogen at $875 \mathrm{~K}$ for $2 \mathrm{~h}$ and followed by post treatment with hydrogen peroxide. It was found that the incorporation of magnesium into the catalyst lattice were greatly affected the catalyst properties as can be clearly seen in the formation of crystalline phases as observed in the XRD. A highly pure orthorhombic M1 phase that is reported important in the catalyst activity for propane oxidation have successfully derived when the loading of $\mathrm{Mg} / \mathrm{Mo}$ was in the molar ratio of 0.06 . Adding less or more that will give mixture of phases with the present of tetragonal phase became more dominant. The Mg-doped catalysts show a high reducibility property when subjected to reducing agent which is an important property for an oxidation catalyst. The oxygen in the doped catalysts are more labile to be removed at lower temperature with high amount of oxygen removable as the consequence of the weak interaction of the oxygen with the Mg species over the surface of the catalyst.

\section{Acknowledgement}

The authors would like to thank the Ministry of Higher Education Malaysia (Fundamental Research Grant Scheme (FRGS), grant number: 5524811) for their financial support.

\section{References}

1. Ushikubo, T., Nakamura, H., Koyasu, Y. and Wajiki, S. (1997). US Patent 5,380,933 (1995). Mitsubishi Kasei Corporation.

2. Popova, G. Y., Andrushkevich, T., Chesalov, Y. A., Plyasova, L., Dovlitova, L., Ischenko, E. and Khramov, M. (2009). Formation of active phases in MoVTeNb oxide catalysts for ammoxidation of propane. Catalysis Today, 144(3): 312 - 317.

3. Amakawa, K., Kolen'ko, Y. V., Villa, A., Schuster, M. E., Csepei, L.-I., Weinberg, G. and Prati, L. (2013). Multifunctionality of crystalline $\mathrm{MoV}(\mathrm{TeNb}) \mathrm{M} 1$ oxide catalysts in selective oxidation of propane and benzyl alcohol. ACS Catalysis, 3(6): 1103 - 1113.

4. Ushikubo, T., Oshima, K., Kayou, A. and Hatano, M. (1997). Ammoxidation of propane over Mo-V-Nb-Te mixed oxide catalysts. Studies in Surface Science and Catalysis, 112: 473 - 480.

5. Asakura, K., Nakatani, K., Kubota, T. and Iwasawa, Y. (2000). Characterization and kinetic studies on the highly active ammoxidation catalyst MoVNbTeOx. Journal of Catalysis, 194(2): 309 - 317.

6. Tsuji, H. and Koyasu, Y. (2002). Synthesis of MoVNbTe(Sb)Ox composite oxide catalysts via reduction of polyoxometalates in an aqueous medium. Journal of the American Chemical Society, 124(20): 5608 - 5609.

7. Oliver, J., Nieto, J. L., Botella, P. and Mifsud, A. (2004). The effect of pH on structural and catalytic properties of MoVTeNbO catalysts. Applied Catalysis A: General, 257(1): 67 - 76.

8. Grasselli, R. K., Burrington, J. D., Buttrey, D. J., DeSanto Jr, P., Lugmair, C. G., Volpe Jr, A. F. and Weingand, T. (2003). Multifunctionality of active centers in (amm) oxidation catalysts: from $\mathrm{Bi}-\mathrm{Mo}-\mathrm{O} \times$ to Mo-V-Nb-(Te, Sb)-Ox. Topics in Catalysis, 23(1-4): 5 - 22.

9. García-González, E., López Nieto, J., Botella, P. and González-Calbet, J. (2002). On the nature and structure of a new MoVTeO crystalline phase. Chemistry of Materials, 14(10): 4416 - 4421.

10. Tsuji, H., Oshima, K. and Koyasu, Y. (2003). Synthesis of molybdenum and vanadium-based mixed oxide catalysts with metastable structure: Easy access to the $\mathrm{MoVNbTe}(\mathrm{Sb}) \mathrm{Ox}$ catalytically active structure using reductant and oxoacid. Chemistry of Materials, 15(11): 2112 - 2114.

11. Ueda, W. and Oshihara, K. (2000). Selective oxidation of light alkanes over hydrothermally synthesized MoVMO (M= Al, Ga, Bi, Sb, and Te) oxide catalysts. Applied Catalysis A: General, 200(1), 135 - 143. 
12. Grasselli, R. K., Buttrey, D. J., DeSanto, P., Burrington, J. D., Lugmair, C. G., Volpe, A. F. and Weingand, T. (2004). Active centers in Mo-V-Nb-Te-O x (amm) oxidation catalysts. Catalysis Today, 91: $251-258$.

13. Grasselli, R. K. (2005). Selectivity issues in (amm) oxidation catalysis. Catalysis Today, 99(1): 23 - 31.

14. Ueda, W., Vitry, D., Kato, T., Watanabe, N. and Endo, Y. (2006). Key aspects of crystalline Mo-VO-based catalysts active in the selective oxidation of propane. Research on Chemical Intermediates, 32(3): 217 - 233.

15. Schacht, L., Navarrete, J., Schacht, P. and Ramírez, M. A. (2010). Influence of Vanadium oxidation states on the performance of $\mathrm{V}-\mathrm{Mg}$-Al mixed-oxide catalysts for the oxidative dehydrogenation of propane. Journal of the Mexican Chemical Society, 54(2): 69 - 73.

16. Pless, J. D., Bardin, B. B., Kim, H.-S., Ko, D., Smith, M. T., Hammond, R. R. and Poeppelmeier, K. R. (2004). Catalytic oxidative dehydrogenation of propane over Mg-V/Mo oxides. Journal of Catalysis, 223(2): 419 431.

17. Lee, K., Yoon, Y.-S., Ueda, W. and Moro-Oka, Y. (1997). An evidence of active surface MoOx over MgMoO4 for the catalytic oxidative dehydrogenation of propane. Catalysis Letters, 46(3-4): 267 - 271.

18. Yoon, Y. S., Ueda, W. \& Moro-oka, Y. (1995). Oxidative dehydrogenation of propane over magnesium molybdate catalysts. Catalysis Letters, 35(1-2): 57 - 64.

19. Cadus, L., Gomez, M. and Abello, M. (1997). Synergy effects in the oxidative dehydrogenation of propane over $\mathrm{MgMoO}_{4}-\mathrm{MoO}_{3}$ catalysts. Catalysis Letters, 43(3-4): 229 - 233.

20. Morales, E. and Lunsford, J. H. (1989). Oxidative dehydrogenation of ethane over a lithium-promoted magnesium oxide catalyst. Journal of Catalysis, 118(1): 255 - 265.

21. Conway, S. J. and Lunsford, J. H. (1991). The oxidative dehydrogenation of ethane over chlorine-promoted lithium-magnesium oxide catalysts. Journal of Catalysis, 131(2): 513 - 522.

22. Mahdavi, V. \& Hasheminasab, H. R. (2015). Liquid-phase efficient oxidation of cyclohexane over cobalt promoted VPO catalyst using tert-butylhydroperoxide. Journal of the Taiwan Institute of Chemical Engineers, 51: $53-62$.

23. Ivars, F., Solsona, B., Botella, P., Soriano, M. and Nieto, J. L. (2009). Selective oxidation of propane over alkali-doped Mo-V-Sb-O catalysts. Catalysis Today, 141(3): 294 - 299.

24. Botella, P., Concepción, P., Nieto, J. L. and Solsona, B. (2003). Effect of potassium doping on the catalytic behavior of Mo-V-Sb mixed oxide catalysts in the oxidation of propane to acrylic acid. Catalysis Letters, 89(34): 249 - 253.

25. Ivars, F., Solsona, B., Soriano, M. and Nieto, J. L. (2008). Selective oxidation of propane over AMoVSbO catalysts $(\mathrm{A}=\mathrm{Li}, \mathrm{Na}, \mathrm{K}, \mathrm{Rb}$ or $\mathrm{Cs})$. Topics in Catalysis, 50(1-4): 74 - 81.

26. Ueda, W., Endo, Y. and Watanabe, N. (2006). K-doped Mo-V-Sb-O crystalline catalysts for propane selective oxidation to acrylic acid. Topics in Catalysis, 38(4), $261-268$.

27. Sanfiz, A. C., Hansen, T. W., Girgsdies, F., Timpe, O., Rödel, E., Ressler, T. and Schlögl, R. (2008). Preparation of phase-pure M1 MoVTeNb oxide catalysts by hydrothermal synthesis-influence of reaction parameters on structure and morphology. Topics in Catalysis, 50(1-4): 19 - 32.

28. Vitry, D., Morikawa, Y., Dubois, J. and Ueda, W. (2003). Mo-V-Te-(Nb)-O mixed metal oxides prepared by hydrothermal synthesis for catalytic selective oxidations of propane and propene to acrylic acid. Applied Catalysis A: General, 251(2): 411 - 424.

29. Lin, M. M. (2003). Complex metal-oxide catalysts for selective oxidation of propane and derivatives: I. Catalysts preparation and application in propane selective oxidation to acrylic acid. Applied Catalysis A: General, 250(2): 305 - 318.

30. Tu, X., Furuta, N., Sumida, Y., Takahashi, M. and Niiduma, H. (2006). A new approach to the preparation of MoVNbTe mixed oxide catalysts for the oxidation of propane to acrylic acid. Catalysis Today, 117(1): 259 264.

31. Irmawati, R., Ahmad Afandi, M., Ahmad Zaidi, I. and Hossein Abbastabar, A. (2011). Patent pending No. PI2011003855.

32. Evans Jr, H. T. (1968). Refined molecular structure of the heptamolybdate and hexamolybdotellurate ions. Journal of the American Chemical Society, 90(12): 3275 - 3276.

33. Sun, Y., Liu, J. and Wang, E. (1986). Preparation and properties of some new 6-heteropoly-tellurate compounds of tungsten and molybdenum containing vanadium. Inorganica Chimica Acta, 117(1): 23 - 26. 
34. Ratheesh, R., Suresh, G. and Nayar, V. (1995). Infrared and polarized raman spectra of $\mathrm{M} 6\left[\mathrm{TeMo}_{6} \mathrm{O}_{24}\right] \cdot 7 \mathrm{H}_{2} \mathrm{O}$ $\left[\mathrm{M}=\mathrm{K}, \mathrm{NH}_{4}\right]$ and $\left(\mathrm{NH}_{4}\right)_{6}\left[\mathrm{TeMo}_{6} \mathrm{O}_{24}\right] \cdot \mathrm{Te}(\mathrm{OH})_{6} \cdot 7 \mathrm{H}_{2} \mathrm{O}$ single crystals. Journal of Solid State Chemistry, $118(2)$ : $341-356$.

35. Botto, I., Cabello, C. and Thomas, H. (1997). $\left(\mathrm{NH}_{4}\right)_{6}\left[\mathrm{TeMo}_{6} \mathrm{O}_{24}\right] \cdot 7 \mathrm{H}_{2} \mathrm{O}$ Anderson phase as precursor of the $\mathrm{TeMo}_{5} \mathrm{O}_{16}$ catalytic phase: thermal and spectroscopic studies. Materials Chemistry and Physics, 47(1): 37 - 45.

36. Botella, P., Nieto, J. L. and Solsona, B. (2002). Selective oxidation of propene to acrolein on Mo-Te mixed oxides catalysts prepared from ammonium telluromolybdates. Journal of Molecular Catalysis A: Chemical, 184(1): 335 - 347.

37. Nakamoto, K. (1970). Infrared spectra of inorganic and coordination compounds. $2^{\text {nd }}$ Edition. Wiley Science, New York.

38. Lin, M. M. (2003). Complex metal oxide catalysts for selective oxidation of propane and derivatives: II. The relationship among catalyst preparation, structure and catalytic properties. Applied Catalysis A: General, 250(2): $287-303$.

39. Deniau, B., Millet, J., Loridant, S., Christin, N. and Dubois, J. (2008). Effect of several cationic substitutions in the M1 active phase of the MoVTeNbO catalysts used for the oxidation of propane to acrylic acid. Journal of Catalysis, 260(1): 30 - 36.

40. Ischenko, E., Andrushkevich, T., Popova, G. Y., Bondareva, V., Chesalov, Y., Kardash, T. Y. and Ischenko, A. (2010). Formation of active component of MoVTeNb oxide catalyst for selective oxidation and ammoxidation of propane and ethane. Studies in Surface Science and Catalysis, 175: 479 - 482.

41. Popova, G. Y., Andrushkevich, T., Aleshina, G., Plyasova, L. and Khramov, M. (2007). Effect of oxalic acid content and medium of thermal treatment on physicochemical and catalytic properties of MoVTeNb oxide catalysts in propane ammoxidation. Applied Catalysis A: General, 328(2): 195 - 200.

42. Magneli, A. (1953). Studies on the hexagonal tungsten bronzes of-potassium. Acta Chemica Scandinavica, 7: $315-324$.

43. Girgsdies, F., Schlögl, R. and Trunschke, A. (2012). In-situ X-ray diffraction study of phase crystallization from an amorphous MoVTeNb oxide catalyst precursor. Catalysis Communications, 18: 60 - 62.

44. Murayama, H., Vitry, D., Ueda, W., Fuchs, G., Anne, M. and Dubois, J. (2007). Structure characterization of orthorhombic phase in MoVTeNbO catalyst by powder X-ray diffraction and XANES. Applied Catalysis A: General, 318: 137 - 142.

45. Deniau, B., Bergeret, G., Jouguet, B., Dubois, J. and Millet, J. (2008). Preparation of single M1 phase $\mathrm{MoVTe}(\mathrm{Sb}) \mathrm{NbO}$ catalyst: Study of the effect of M2 phase dissolution on the structure and catalytic properties. Topics in Catalysis, 50(1-4): 33 - 42.

46. Bart, J., Cariati, F. and Sgamellotti, A. (1979). Mixed-valence effects in tellurium-molybdenum oxides. Inorganica Chimica Acta, 36: 105 - 112.

47. Bart, J., Petrini, G. and Giordano, N. (1975). Solid-state equilibrium relations in the Ternary Systems $\mathrm{TeO}_{2}$ $\mathrm{MoO}_{3}-\mathrm{MoO}_{2}$ and $\mathrm{TeO}_{2}-\mathrm{MoO}_{3}-\mathrm{Te}$. Zeitschrift für anorganische und allgemeine Chemie, 413(2): 180 - 192.

48. Botella, P., Nieto, J. L., Solsona, B., Mifsud, A. and Márquez, F. (2002). The preparation, characterization, and catalytic behavior of MoVTeNbO catalysts prepared by hydrothermal synthesis. Journal of Catalysis, 209(2): $445-455$.

49. Jiang, H., Lu, W. \& Wan, H. (2004). The effect of $\mathrm{MoV}_{0.3} \mathrm{Te}_{0.23} \mathrm{P}_{\mathrm{x}} \mathrm{O}_{\mathrm{n}}$ catalysts with different phosphorus content for selective oxidation of propane to acrolein. Journal of Molecular Catalysis A: Chemical, 208(1): 213 $-217$.

50. Pereira, E. B., Pereira, M. M., Lam, Y., Perez, C. A. and Schmal, M. (2000). Synthesis and characterization of niobium oxide layers on silica and the interaction with nickel. Applied Catalysis A: General, 197(1): 99 - 106.

51. Ramli, I., Botella, P., Ivars, F., Meng, W. P., Zawawi, S. M. M., Ahangar, H. A. and Nieto, J. M. L. (2011). Reflux method as a novel route for the synthesis of MoVTeNbOx catalysts for selective oxidation of propane to acrylic acid. Journal of Molecular Catalysis A: Chemical, 342: 50 - 57. 